\title{
Influence of bound water on the interaction of the same-nature and different- nature chemical groups of drugs and receptors
}

Authors: Felix S. Dukhovich ${ }^{1+}$, Mikhail B. Darkhovskii ${ }^{2, *}$

\author{
Affiliations: \\ ${ }^{1}$ Independent Scholar \\ ${ }^{2}$ InterX Inc. \\ * Correspondence to: mikhail.darkhovskiy@interxinc.com
}

\section{Abstract}

Formation of a stable ligand-receptor complex is possible only in the case of complete displacement of water molecules from the contact place. Non-displaced (bound) water increases not only distance between the interacting molecules, but also dielectric permittivity of the medium impeding complex formation. Another aspects of the effect of water also exist. They are related to the fact that different molecules and groups from which they are composed acquire hydrate shells of different strength in aqueous solutions. For example, bonding between water molecules and ionic groups is much stronger than between water molecules and dipole or non-polar groups. In this paper the method for calculation of the effect of bound water molecules on the affinity of a drug for neuroreceptors is presented. We demonstrate that the bound water is directly involved in recognition of the specific (complementary) receptor by the drug, because it prevents drug losses on non-specific receptors.

The effect of water on stability of the complex is determined by comparing potential energy of the direct binding of various groups in the composition of a drug molecule to the receptor with the energy of hydration of these groups. Interactions between the same-type groups and different types of groups are considered. As a former we consider the interactions between ionic groups, and the latter are represented by the interactions of ionic groups with dipole ones. Literature data on the free energy changes $(\Delta \mathrm{G})$ occurring during binding of the same-type groups and of the different types of groups are also discussed. 
Keywords: receptor-ligand interactions, bound water, intermolecular energy, watermediated recognition, drug-receptor recognition

\section{Introduction}

Role of water in thermodynamic of molecular recognition processes in the binding of a ligand to a receptor is extremely important. However, there is still a significant lack of specific knowledge to the extent of water influence on the process.

\section{Methods}

\section{Potential energy of interaction of ionic groups in drugs and receptors}

The results of calculations of the potential energy of interaction of the cationic groups $\mathrm{NH}_{3}{ }^{+}$and $-\mathrm{NH}\left(\mathrm{CH}_{3}\right)_{2}{ }^{+}$that are often found in the structure of drugs with carboxylate anion representing anionic group in the active site of numerous neuroreceptors ${ }^{[1]}$ are presented in Table 1.

Potential energy of interaction between two ions is

$$
\mathrm{E}_{i-i}=\frac{z_{1} z_{2} e^{2}}{d \varepsilon}
$$

where $\mathrm{z}_{1}, \mathrm{z}_{2}$ are valences of ions, $d$ is the distance between ions, $e$ is the electron charge, and $\varepsilon$ is the dielectric constant. If electron charge and distances are measured in electrostatic units and Angstroms $(\AA)$ respectively, then equation (1) can be rewritten for equilibrium distances between monovalent ions as: 


$$
\mathrm{E}_{i-i}=-\frac{305}{d_{e} \varepsilon} \mathrm{kcal} / \mathrm{mol},
$$

where $d_{e}$ is the equilibrium distance between charges. Sign " - " indicates interaction between the oppositely charged ions. For the $d_{e}$ distance, equation (2) takes into account repulsion energy between electron shells of the interacting ions ${ }^{[2]}$. The equilibrium distance is taken equal to the sum of van der Waals radiuses of ionic groups ${ }^{[2]}$. The $d_{e}$ values correspond to the maximum energy of complex formation. Calculations are carried out assuming $\varepsilon=1$.

Electrostatic interactions between ions is the most significant component, but other types of interactions such as, first of all, polarization and dispersion interactions also contribute to the binding energy. In our calculations these contributions are taken into account during consideration of all main types of interactions despite their lower input (equations used for calculations are presented below $\left.{ }^{[2]}\right)$.

\section{Potential energy of interaction of ionic groups with water}

The results of calculating the potential energy of binding ions with water $\mathrm{E}_{\mathrm{i}-\mathrm{w}}$ at the moly ratio "ion:water" equal to 1:1 are given. Removing the two most strongly related water molecules (one from each interacting ions' water shell) is sufficient to make direct contact between the ionic groups at van der Waals distances. Interaction energy with the second layer of the water shell is not considered due to its relatively small contribution ${ }^{[2]}$.

Potential energy of interaction of ion with water $\mathrm{E}_{\mathrm{i}-\mathrm{w}}$ consists of the following components: ion-dipole interaction, ion-induced dipole interaction (polarization), and dispersion interaction ${ }^{[2]}$.

Ion-dipole interaction energy is: 


$$
E_{i-d}=-57.4 \frac{z \mu}{d_{e}^{2} \varepsilon} \cos \theta \quad \mathrm{kcal} / \mathrm{mol} .
$$

where $\mathrm{z}$ is the valence of the ion (in our case, $\mathrm{z}=1$ ), $\mu$ is dipole moment in Debyes (D), for water it is $\mu=1.83$, and it is accepted that $\varepsilon=1$. Maximum energy of the interaction is reached when the center of ion charge and the charges of water dipole are on the same straight line $(\cos \theta=1)$.

Ion-induced dipole interaction energy is:

$$
E_{i-i n d}=-44.1 \frac{R z^{2}}{d_{e}^{4} \varepsilon^{2}} \mathrm{kcal} / \mathrm{mol},
$$

where $\mathrm{R}$ is the molar refraction in $\mathrm{ml} / \mathrm{mol}$.

Dispersion interaction:

$$
E_{\text {disp }}=-18.7 \sqrt[4]{Z_{1} Z_{2}} \frac{R_{1} R_{2}}{d_{e}^{6}} \mathrm{kcal} / \mathrm{mol},
$$

where $Z_{1}, Z_{2}$ are the number of electrons on the outer orbitals of interacting groups or molecules.

It follows from comparing the data presented in Tables 1 and 2 that the bound water molecules are displaced and do not obstruct direct contact of the cationic group with the anionic one.

\section{Potential energy of interaction between ionic groups and dipoles}

Interactions between different types of groups are investigated using ion - dipole interaction as an example. The equations $(3-5)$ are used for calculation $\mathrm{E}_{\mathrm{i}-\mathrm{d} .}$ It was assumed that $\varepsilon=1$. Examples of such calculation are carried out for the interactions between the amide group in a peptide bond

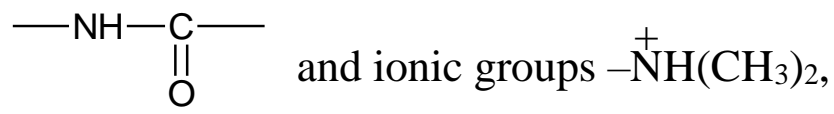
$-\stackrel{+}{\mathrm{N}} \mathrm{H}_{3}$, and $-\mathrm{COO}^{-}$. Charge at the poles of amide group is taken as $0.39 \overline{\mathrm{e}}$, and its dipole moment is $\mu=3.7 \mathrm{D}^{[3]}$. Based on these values the dipole length is calculated to be $l=1.98$ $\AA$ A. It follows from this that the equilibrium distance on direct contact of this group with $-\stackrel{+}{\mathrm{N}} \mathrm{H}\left(\mathrm{CH}_{3}\right)_{2}$ group is $\mathrm{d}_{\mathrm{e}}=5.56 \AA$ (from the side of the nitrogen atom of the ion, which is 
taken as the center of charge in the ion). The equilibrium distance is composed from the following components: $3.17 \AA$ (van der Waals radius of the ionic group), $0.99 \AA$ (dipole center), $1.40 \AA$ (van der Waals radius of oxygen atom). The equilibrium distances between the considered amide group and ionic groups $-\stackrel{+}{\mathrm{N}} \mathrm{H}_{3}$ and $-\mathrm{COO}^{-}$are 4.09 and $4.54 \AA$, respectively. It is not always easy to determine the complex structure, that is why for other dipole groups we used approximate $d_{e}$ values based on their van der Waals radiuses: $4 \AA-$ for interaction with $-\mathrm{N}_{3}^{+} \mathrm{H}_{3}$ and $-\mathrm{COO}^{-}$ions and $5 \AA$ - for interaction with $-\stackrel{+}{\mathrm{N}} \mathrm{H}\left(\mathrm{CH}_{3}\right)_{2}$ cation. Dipole moments for the groups are taken from papers ${ }^{[4,5]}$. It is assumed that dipole groups in the molecules are bound to carbon atoms, hence, refractivity of the terminal bonds is estimated as $1 / 2$ of the refractivity of the bond $\mathrm{C}-\mathrm{C}$ or $\mathrm{N}-\mathrm{C}$ and is added to the refractivity of the main group.

The values of potential energies $\mathrm{E}_{\mathrm{i}-\mathrm{d}}$ of direct interaction between ionic groups and dipoles at their molar ratio 1:1 are presented in Table 3.

\section{Potential energy of interaction of dipole groups with water}

The calculated values of potential energy of interactions of investigated dipole groups with water, $E_{\mathrm{d}-\mathrm{w}}$, are presented in Table 4 . The following equation is used for calculating $E_{d-w}$ energy ${ }^{[2]}$

$$
E_{\mathrm{d}-\mathrm{w}}=-10.8 A \frac{\mu \mu_{w}}{d_{e}^{3} \varepsilon} \quad \mathrm{kcal} / \mathrm{mol}
$$

Parameter $A$ accounts for the ratio between $d_{\mathrm{e}}$ and dipole length. The value of $\varepsilon$ for $\mathrm{d}_{\mathrm{e}}$ is taken as $1^{[2]}$. It is assumed that the charge poles in the dipole groups and in water molecules are located along a straight line (head-to-tail). Molar ratio 'dipole - water' is taken to be 1:1. The $d_{e}$ value for the contact of the amide group with water is calculated as $4.06 \AA$, based on the $2.39 \AA$ corresponding this group and $1.67 \AA$ corresponding to water molecule. 
An average $d_{e}$ value of $3.5 \AA$ is used for other dipole groups, which is based on their van der Waals radiuses.

\section{Effect of bound water on complex formation}

The data in Table 5 in which the total energy of hydration of the interacting ion and dipole $\left(\mathrm{E}_{\mathrm{w}}\right)$ is compared with the energy of direct ion-dipole binding, $\mathrm{E}_{\mathrm{i}-\mathrm{d}}$, can provide indication on whether complex formation is a favorable process or not. Difference between these values determined possibility of the complex formation between an ionic group and dipole. It follows from calculations presented in Table 5 that complex formation between ionic groups with dipoles is unfavorable, because the energy of hydration is higher than the energy of direct interaction of these groups. This conclusion does not mean that the dipole cannot be bound to an ionic group at all. Displacement of the bound water molecules could be mediated by other groups; however, such interaction will result in a significant weakening of the complex.

In reality interacting groups are surrounded with a larger number of water molecules than present in our model, which includes only two water molecules. Addition of water molecules bound to ionic and dipole groups can only enhance unfavourability of the contact between these groups. As a matter of fact, the value of $\mathrm{E}_{\mathrm{i}-\mathrm{d}}$ is constant for the given pair of groups, while the value of $E_{\mathrm{w}}$ increases (in absolute values) with addition of extra water molecules. Hence, it can be stated that our model characterizes interactions of ionic groups with dipoles in an aqueous medium. 


\section{Discussion}

Conclusion regarding the important role played by water molecules in the recognition process is corroborated by the experimental results ${ }^{[6]}$ presented in Table 6 . The data on binding of indole derivatives in aqueous medium with melatonin receptor that does not contain any ionic groups in its active center ${ }^{[7]}$ are presented in this Table. The same-type groups are represented by the dipole acetamide group of the ligands 1, 2, 3, 6, and dipole acetamide group of the side chain of the Gln172 residue in the receptor ${ }^{[7]}$, or another dipole group, which are bound to each other and oriented correspondingly. The different types of groups are represented by ionic groups of the ligands 4, 5 and non-ionic group in the receptor. Introduction of ionic groups, both cationic and anionic, into melatonin molecule and its analogues results in a sharp drop of affinity, which becomes practically nonexistent. Neutralization of the charge by $\mathrm{N}$-acetylation adjusts the compounds to the melatonin receptor, and that is why affinity of $\mathrm{N}$-acetylserotonin (6) is significantly higher than of serotonin itself (4). Introduction of non-ionic substituents into the melatonin molecule affects its affinity only slightly.

The presented examples indicate that interactions of the different types of groups not only are practically absent, but also that the presence of these groups prevents binding of the entire molecules.

The data in Table 6 are even more convincing than the data in Table 5, as they represent $\mathrm{K}_{\mathrm{d}}$ values obtained experimentally and, hence, reflect the changes of free energy, $\Delta \mathrm{G}$, which take into consideration all the factors involved in the formation of complexes between compounds and receptors in aqueous medium. However, the calculation model we have proposed is useful for expressly assessing the impact of different ligand groups on complex formation. 
Thus, the characteristic differences in binding of the same-type or different types of groups in the drugs and in the receptors have been convincingly validated.

The results reported in [8] are of interest in context of our findings. The authors examine the model for evaluation of free energy of interactions between the ligand and its binding group in a protein in aqueous solution depending on the nature of the group - charged or non-polar. The calculated values of the binding free energy demonstrate that the interaction "non-polar ligand - non-polar group" and "charged ligand - oppositely charged group" are favorable, while the interactions of the charged groups with non-polar ones are absolutely unfavorable.

We limited ourselves in his study to consideration of binding of the same-type groups and of different types of groups with dipole groups. However, one can argue that interactions between the other types of different groups such as "ion - nonpolar group" and "dipole nonpolar group" would be also unfavorable. Bound water represents one of the main factors of recognition of specific receptor by the drugs. By decreasing lifetimes of the complexes of drugs with various types of receptors, the bound water prevents non-specific losses of drugs in an organism thus facilitating recognition of their 'specific' receptors. The dependencies of the lifetimes of complexes on the $K_{d}$ values for different types of interactions are presented in ${ }^{[9,10]}$.

\section{Conflict Of Interest}

The authors declare no conflicts of interest.

\section{Authors Contribution}

F.S.D. conceived a hypothesis. M.B.D performed a research. F.S.D. and M.B.D. designed the model calculation outline, performed the calculations, analyzed the data, and wrote the paper. 


\section{REFERENCES}

1. Webb JL. Enzyme and Metabolic Inhibitors, v. 1. New York, NY: Academic Press; 1966.

2. Venkatakrishnan AJ, Deupi X, Lebon G, et al. Nature 2013; 494: 185-187.

3. Cantor CR, Schimmel PR. Biophysical Chemistry, v.1. W. H. Freeman and Co; 1980.

4. Moelwyn-Hughes EA. Proc. Cambridge Phil. Soc. 1949; 45: 477-512.

5. Minkin VI, Osipov OA, and Zhdanov YA. Dipole moments in organic chemistry. Leningrad: Khimiya; 1968.

6. Dubocovich ML, Takahashi JS. Proc. Natl. Acad. Sci. USA 1987; 84: 3916-3928.

7. Stauch, B., Johansson LC, McCorvy JD., et al. 2019 Nature; 569: 284-307.

8. Baron R, Setny P, McCammon JA. J. Am. Chem. Soc. 2010; 132: 12091-12097.

9. Dukhovich FS, Darkhovskii MB, Gorbatova EN, et al. Pharm. Chem. J. 2002; 36(5): 248-259.

10. Dukhovich FS, Darkhovskii MB, Gorbatova EN, et al. Molecular Recognition: Pharmacological Aspects. New York, NY: Nova Science Publishers; 2004. 


\section{Table 1}

Potential energy of interaction of cationic groups with carboxylate anion $\left(\mathrm{E}_{\mathrm{i}-\mathrm{i}}\right)$

\begin{tabular}{|l|c|c|}
\hline \multirow{2}{*}{ Cationic group } & \multicolumn{2}{|c|}{$-\mathrm{COO}^{-}$} \\
\cline { 2 - 3 } & $\mathrm{d}_{\mathrm{e}}, \AA$ & $\mathrm{E}_{\mathrm{i}-\mathrm{i}}, \mathrm{kcal} / \mathrm{mol}$ \\
\hline$-\mathrm{NH}_{3}{ }^{+}$ & 3.85 & -82.2 \\
\hline$-\mathrm{NH}\left(\mathrm{CH}_{3}\right)_{2}{ }^{+}$ & 5.32 & -58.4 \\
\hline
\end{tabular}

Table 2

Potential energy of binding of ionic groups to water $\left(\mathrm{E}_{\mathrm{i}-\mathrm{w}}\right)$

\begin{tabular}{|l|c|c|}
\hline \multicolumn{1}{|c|}{ Ionic group } & $\mathrm{d}_{\mathrm{e}}, \AA$ & $-\mathrm{E}_{\mathrm{i}-\mathrm{w}}, \mathrm{kcal} / \mathrm{mol}$ \\
\hline$-\mathrm{COO}^{-}$ & 3.82 & 8.36 \\
\hline$-\mathrm{NH}_{3}{ }^{+}$ & 3.37 & 11.32 \\
\hline$-\mathrm{NH}\left(\mathrm{CH}_{3}\right)_{2}{ }^{+}$ & 4.84 & 5.06 \\
\hline
\end{tabular}


Table 3

Potential energy of ionic groups binding to the dipoles ( $\left.\mathrm{E}_{\mathrm{i}-\mathrm{d}}\right)$

\begin{tabular}{|c|c|c|c|}
\hline \multirow{2}{*}{ Dipole } & \multicolumn{3}{|c|}{ - $\mathrm{E}_{\mathrm{i}-\mathrm{d}}, \mathrm{kcal} / \mathrm{mol}$} \\
\hline & $-\mathrm{COO}^{-}$ & $-\mathrm{NH}_{3}{ }^{+}$ & $-\mathrm{NH}\left(\mathrm{CH}_{3}\right)_{2}{ }^{+}$ \\
\hline$-\mathrm{NH}-\underset{\mathrm{O}}{\mathrm{C}}-$ & 11.47 & 14.59 & 7.55 \\
\hline$-\mathrm{CH}_{2} \mathrm{OCH}_{2}-$ & 7.6 & 7.2 & 4.6 \\
\hline$-\mathrm{CH}_{2} \mathrm{OH}$ & 8.0 & 8.0 & 4.8 \\
\hline$-\mathrm{CH}_{2} \mathrm{CH}_{\mathrm{O}}^{\mathrm{CH}_{2}-}$ & 12.0 & 10.0 & 8.5 \\
\hline$-\|_{\mathrm{O}}^{\mathrm{C}-\mathrm{O}-}$ & 8.1 & 8.1 & 5.0 \\
\hline$-\mathrm{CH}=\mathrm{O}$ & 11.3 & 11.3 & 6.5 \\
\hline $\mathrm{H}_{2} \mathrm{C}=\mathrm{O}$ & 10.8 & 11.8 & 6.7 \\
\hline
\end{tabular}


Table 4

Potential energy of hydration of dipole groups $\left(\mathrm{E}_{\mathrm{d}-\mathrm{w}}\right)$. Dipole $: \mathrm{H}_{2} \mathrm{O}=1: 1$

\begin{tabular}{|c|c|}
\hline Dipole group & $-\mathrm{E}_{\mathrm{d}-\mathrm{w}}, \mathrm{kcal} . \mathrm{mol}$ \\
\hline$-\mathrm{NH}-\underset{\mathrm{C}}{\mathrm{O}}$ & 3.32 \\
\hline$-\mathrm{CH}_{2} \mathrm{OCH}_{2}-$ & 2.55 \\
\hline$-\mathrm{CH}_{2} \mathrm{OH}$ & 1.63 \\
\hline$-\mathrm{CH}_{2} \mathrm{CH}_{2}^{-}$ \\
\hline$-\mathrm{CH}_{2}-\mathrm{O}-$ & 4.44 \\
\hline $\begin{array}{l}\mathrm{O} \\
-\mathrm{CH}=\mathrm{O}\end{array}$ & 2.42 \\
\hline $\mathrm{H}_{2} \mathrm{C}=\mathrm{O}$ & 2.94 \\
\hline
\end{tabular}


Table 5

Potential energy of complex formation between ionic groups and dipole $\left(\mathrm{E}_{\mathrm{i}-\mathrm{d}}\right)$ and potential energy of hydration of these groups ( $\left.\mathrm{E}_{\mathrm{W}}\right)$.

Values presented in $\mathrm{kcal} / \mathrm{mol}$

\begin{tabular}{|c|c|c|c|c|c|c|c|c|c|}
\hline Ion & & $-\mathrm{CO}$ & & & $-\mathrm{NH}$ & & & $-\mathrm{NH}$ & $\left.\mathrm{H}_{3}\right)_{2}^{+}$ \\
\hline Dipole & $-E_{i-d}$ & $-\mathrm{E}_{\mathrm{W}}$ & $E_{i-d}-E_{W}$ & $-E_{i-d}$ & $-\mathrm{E}_{\mathrm{W}}$ & $E_{i-d}-E_{W}$ & $-E_{i-d}$ & $-\mathrm{E}_{\mathrm{W}}$ & $E_{i-d}-E_{W}$ \\
\hline$-\mathrm{NH}-\underset{\mathrm{O}}{\mathrm{C}}-$ & 11.47 & 11.66 & 0.19 & 14.59 & 14.64 & 0.05 & 7.55 & 8.38 & 0.83 \\
\hline$-\mathrm{CH}_{2} \mathrm{OCH}_{2}-$ & 7.6 & 10.9 & 2.2 & 7.2 & 13.9 & 6.7 & 4.6 & 7.6 & 3.0 \\
\hline$-\mathrm{CH}_{2} \mathrm{OH}$ & 8.0 & 10.0 & 2.0 & 8.0 & 13.0 & 5.0 & 4.8 & 9.9 & 5.1 \\
\hline$-\mathrm{CH}_{2} \mathrm{C}_{\mathrm{O}} \mathrm{CH}_{2}-$ & 12.0 & 12.8 & 0.8 & 10.0 & 15.8 & 5.8 & 8.5 & 9.5 & 1.0 \\
\hline$-\mathrm{C}-\mathrm{O}-$ & 8.1 & 10.8 & 2.7 & 8.1 & 13.7 & 5.6 & 5.0 & 7.5 & 2.5 \\
\hline$-\mathrm{CH}=\mathrm{O}$ & 11.3 & 11.3 & 0.9 & 11.3 & 14.3 & 3.0 & 6.5 & 8.0 & 1.5 \\
\hline $\mathrm{H}_{2} \mathrm{C}=\mathrm{O}$ & 10.8 & 11.4 & 0.6 & 11.8 & 14.4 & 2.6 & 6.7 & 8.1 & 1.4 \\
\hline
\end{tabular}


Table 6

Affinities of indole derivatives to melatonin receptors (adapted from ${ }^{[6]}$ )

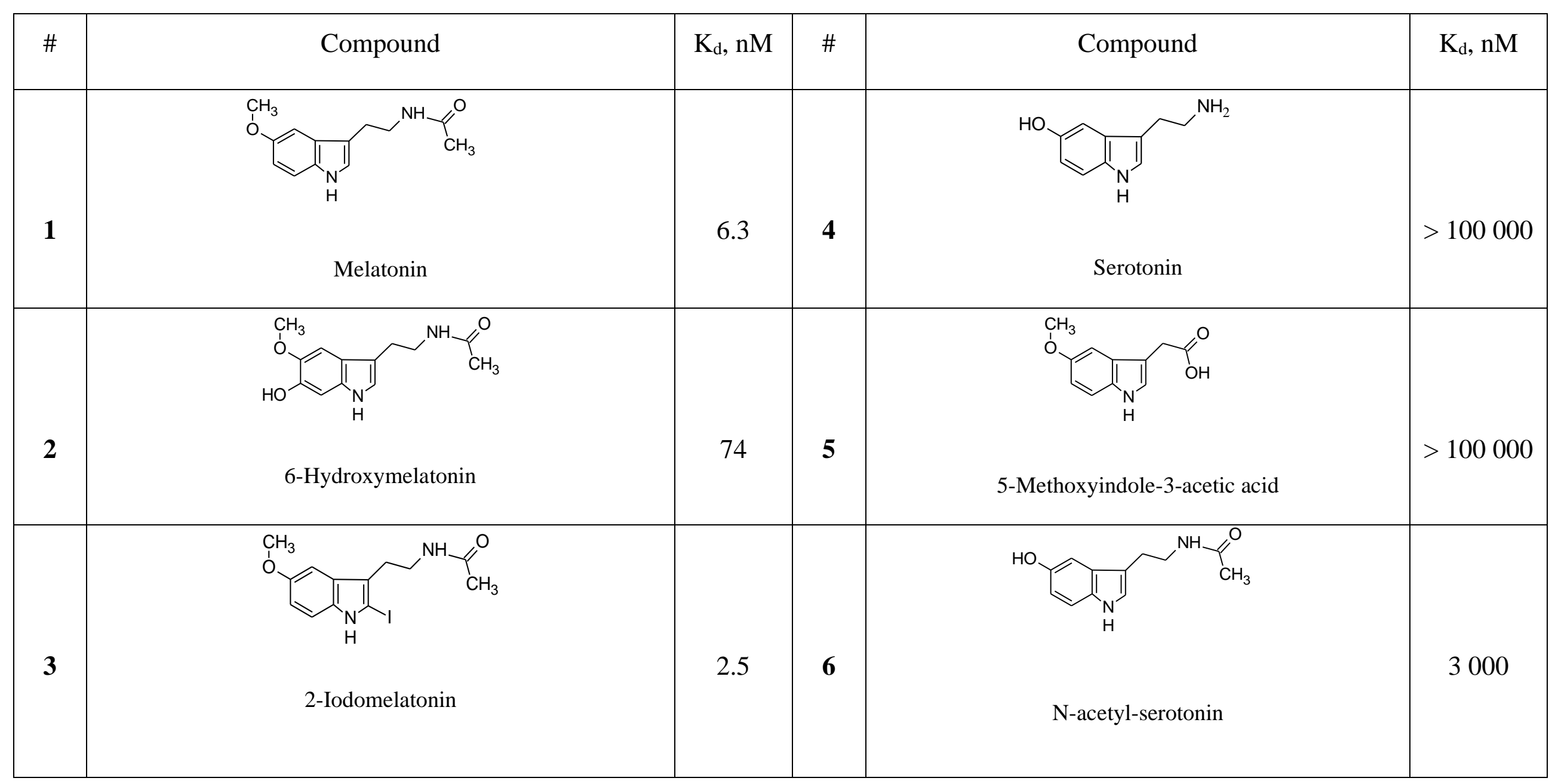


